\title{
The Development of a Test to Explore the Students' Mental Models and External Representation Patterns of Hanging Objects
}

\author{
Sarintan N. Kaharu' ${ }^{1}$, and Jusman Mansyur ${ }^{1}$ \\ ${ }^{1}$ Tadulako University, Indonesia
}

\begin{abstract}
This study aims to develop a test that can be used to explore mental models and representation patterns of objects in liquid fluid. The test developed by adapting the Reeves's Development Model was carried out in several stages, namely: determining the orientation and test segments; initial survey; preparation of the initial draft; try out; expansion of coverage; expert validation; trial and proving validity-reliability; and test finalization. The content and construct validity were determined by involving two experts as raters. The test reliability was determined using Cohen's Kappa (к), which involved 62 students and combined the test-retest and inter-rater methods to determine the consistency of students' responses. The developed test consists of 30 items covering the context of floating, sinking, and hanging objects. The hanging objects are dominant context of the test. The results showed that in the development process, the test has very good validity, and high reliability. The test can be used to explore mental models and external representation patterns on students in elementary, junior, senior high schools and undergraduate. Furthermore, limitations of the test are also presented in this paper.
\end{abstract}

Keywords: Keywords: external representation; hanging, mental model; reliability; validity.

\section{INTRODUCTION}

Students tend to share previous knowledge of science, following their experiences, textbooks, teacher explanations, or everyday language (Ünal \& Coştu, 2005). According to constructivists, students often build their knowledge and theories on how the world works naturally. Therefore, their knowledge of construction or conception is sometimes at odds with theories understood by scientists (Larsson, 2016).

Several studies in science education explore how students think in scientific topics, such as their explanations on some objects float in water, while others sink, etc. (Duit, 2007). Minogue and Borland (2016) reported that students often focus on only one dimension. They refer to the mass of an object (a light object will float) to its volume (a large object will sink), or to its shape (anything with a hole in it will sink).

Kohn (1993) showed similarities between preschool children and adults related to their inadequate strategies for assessing floating or sinking objects. The topics of density and buoyancy are often introduced only in secondary schools based on the argument that students should be able to understand the formal aspects from a formula involved such as proportion (comparison of quantities). There were even high school students who have the same conception through an intuitive approach Smith, Maclin, Grosslight and Davis (1997).

Similarly, Havu-Nuutinen (2005), Chien, Hsiung and Chen (2009), Shen, Liu and Chang (2017), Shivakumar (2016), and Teo, Yan and Ong (2017) examined the concept of the object properties and state in liquid fluid on floating and sinking objects. Castillo, Waltzer and Kloos (2017) carried out a study focusing on predictions related to the sinking of an object. Qonita et al. (2019) examined teachers' learning process to improve their scientific process skills in building floating and sinking concepts. Viyanti, Cari, Sunarno and Prasetyo (2017) and Kafiyani Samsudin and Saepuzaman (2019) developed assessments related to these two topics, and a diagnostic test in the form of a four-tier test to explore the student's mental models of static fluid, respectively. Gette, Kryjevskaia and Heron (2018) modified the "5-block problem" of Heron, Loverude, Shaffer and McDermott (2003) by shifting the focus of the mass context to density to track students reasoning with a dual-process theory approach related to buoyancy.

Based on the description above, it can be stated that in general, previous studies have focused on floating or sinking objects. The study of mental models and representation of objects in fluid, especially hanging objects, has not received

Corresponding Author e-mail: jusman_mansyur@untad.ac.id https://orcid.org/0000-0001-6126-5692

How to cite this article: Kaharu SN, Mansyur J (2021). The Development of a Test to Explore the Students' Mental Models and External Representation Patterns of Hanging Objects . Pegem Journal of Education and Instruction, Vol. 11, No. 4, 2021, 110-125

Source of support: Nil

Conflict of interest: None.

DOI: $10.47750 /$ pegegog.11.04.11

Received: 13.06 .2021

Accepted: 18.08.2021 Publication: 01.10.2021 
the attention of the researchers. The concept of the hanging object is only associated with the similarity between the density of the object and the density of water. Aspects related to the presentation or representation of the object are not introduced. It can be presumed that the presentation of the hanging object in the liquid being always in the middle of the depth of the liquid, influenced their mental model of the object.

The formation of the mental model is thought to be influenced by textbooks, the habits of teachers in class, or teachers using models from textbooks (Harrison, 2001). Another possibility is the students use an intuitive approach and over-generalize based on the properties and representation of floating and sinking objects as indicated by Adbo and Taber (2009) in chemistry. Students then form their mental model from the desired target knowledge so that a student's model is formed (Duit, 2007). This model may contradict with the scientific model.

Hegarty, Stieff and Dixon (2013) stated that the mental model plays a role in the learning process because learning, in general, can be seen as mental modeling. The mental model provides valuable information about phenomena from the conceptual framework, or the structure of the underlying knowledge. The mental model can be viewed as an internal conceptual representation that is relatively durable and accessible but limited from a system (Scott, Cavana \& Cameron, 2016).

When a person interacts with a system, it means that he acquires knowledge about its operation and the structural relationships between its components. The term mental model is used by researchers in different fields to examine a variety of tasks. There is no agreement on the exact definition of the mental model, however, in general, the term denotes the internal representation that people form towards the environment through their interactions. The most influential and formulated theory in cognitive psychology is the mental models by Johnson-Laird (Johnson-Laird, 2001). The theory provides a general explanation of the human mind, which asserts that humans describe the world by interacting through mental models. In children, mental models are concerned with reasoning about natural transformations and barriers to representational flexibility (van Schijndel, van Es, Franse, van Bers \& Rajmakers, 2018).

Furthermore, mental models are intrinsic representations of objects, ideas, or development produced by individuals during the cognitive processes (Buckley \& Boulter, 2000; Harrison \& Treagust, 2000). Individuals use these models to reason, explain, predict phenomena and produce expressed models also known as external representations in various formats such as verbal descriptions, diagrams, simulations and concrete models to communicate their ideas to others or solve problems (Buckley \& Boulter, 2000; Greca \& Moreira, 2000;
Harrison \& Treagust, 2000). This was confirmed by a research carried out by Nongkhunsarn, Yuenyong, Tupsai and Sranamkam (2019) which showed that the mental models in grade 11 students on fluids can be represented in verbal, equation, and picture forms. Based on these descriptions, it can be stated that mental models are closely related to external representations, which in turn provides a framework for the mental model exploration.

There is no study linking the conception with mental models and representation of objects hanging in fluid. It can be presumed that apart from the consideration of cognitive development, especially in children, the review of the conception of objects in fluid only for the floating and sinking state is probably based on the assumption that if the two concepts are studied, the concept of hanging is also accommodated.

In the initial exploration of the test developed in this study, it was found that there was a tendency for first-year physics education students to always describe the position of a hanging object in the middle between the water surface and the bottom of the vessel. The students classified objects that are stable near the bottom of the vessel in the sinking category, and those that approach the surface as floating. It can be assumed that the same thing happened at the previous educational levels. Therefore, a systematic study is needed to explore the factors that influence mental model formation and external representation. The study needs the support of specific instrument that can be used at the elementary, secondary, and higher education levels.

This research presents the results of the test development that can be used to explore the mental models and objects representation patterns in a liquid fluid. Although the aspects explicitly presented in this research include floating and sinking objects, it is more specific to hanging objects. The floating and sinking review as part of the test is intended to build a framework for students thinking towards hanging objects, which are probably influenced by their views on floating and sinking. The worthiness of the test is determined by: (1) how was the development process of test, and (2) how were the validity and reliability of the test.

\section{Method}

This research focuses on developing test to explore mental models and external representation patterns of students about objects in liquid fluid. The research adopted the research and development based on the Reeves's Development Model (Reeves, 2000), which was adapted by Cotton, Lockyer, Brickell, and Brickell (2009). However, some further adjustments were made as shown in Figure 1. The test developed in this study based on the scheme consists of 8 stages. 


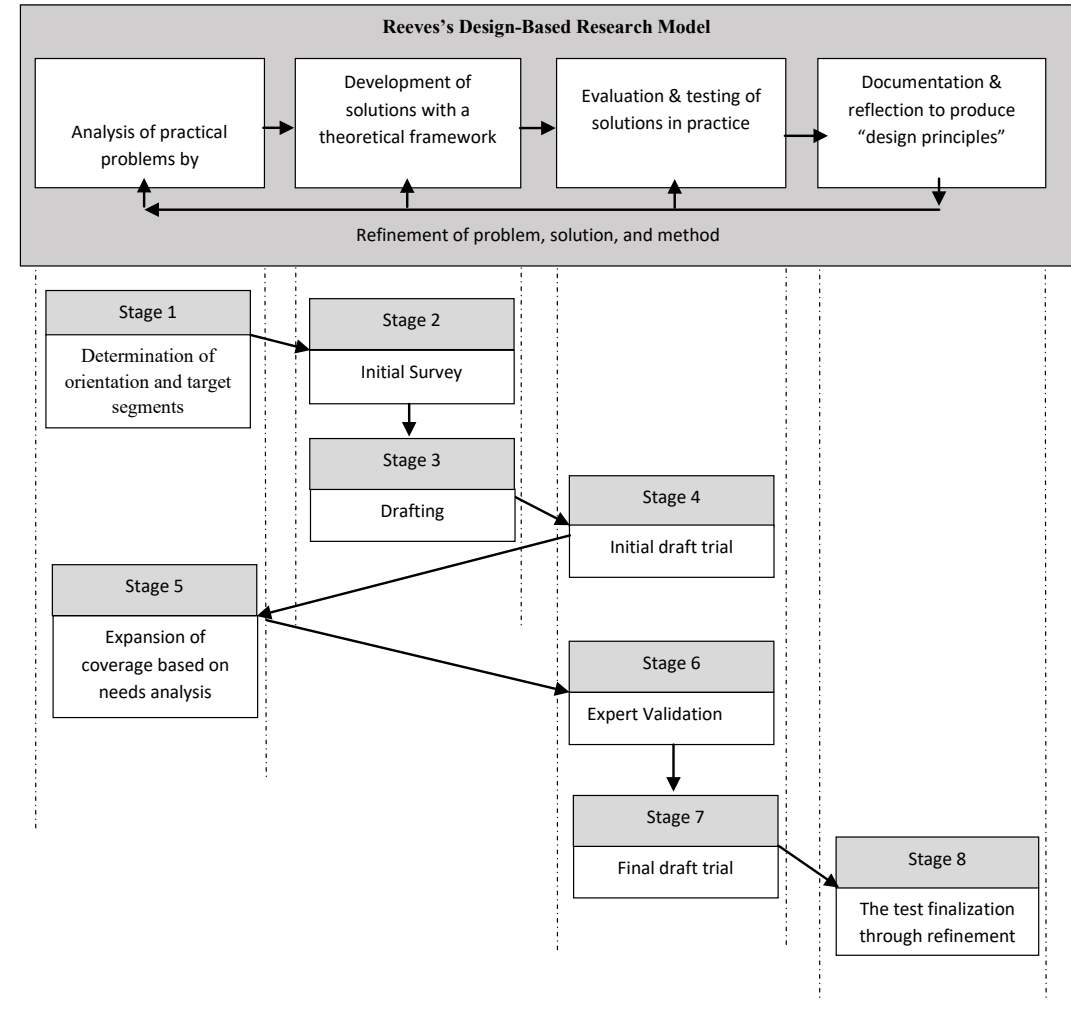

Figure 1: Test development procedure

\section{Stage 1: Determination of Orientation and Test Segment Target}

This stage is based on the initial assumption that people tend to draw hanging objects in liquid fluid following their mental models regarding floating and sinking objects. In other words, drawing hanging objects amid the liquid height at a vessel is influenced by their mental model of floating and sinking objects. Therefore, the purpose of this test is to explore students' mental models related to hanging objects in the liquid fluid. The test is used to explore the mental model development and the external representation patterns of elementary (grade 5-grade 6), junior (grades 7-9), and senior (grade 10-12) high school students. It is also used for prospective physics teachers. In this case, assuming the data is collected within the same timeframe of the students' segment at these levels, the development of mental models and the representation patterns due to students' experience and/or the learning process in the scientific field of physics is observed.

\section{Stage 2: Initial Survey}

The initial survey was carried out by a lecture in Introductory Physics 1 at the Physics Education Study Program, Universitas Tadulako. The survey was carried out simply by asking students to describe the position of floating, sinking, and hanging objects in liquid. The research was focused on students' tendency to draw the position of hanging objects. A temporary conclusion was obtained, which stated that there was a consistent drawing pattern.

\section{Stage 3: Preparation of the Initial Draft}

Based on the temporary conclusion in the initial survey, an initial draft (InitialDraft-1) was composed of two parts. The first was made up of four items, while the second was an item with verbal representation. Furthermore, the five items were changed by making variation, hence InitialDraft- 2 was obtained with a combination of verbal and diagram representation.

\section{Stage 4: Try Out}

From the initial draft preparation, the trial was carried out on 11 students (their major is Physics Education) of the Science Education Master Program, Universitas Tadulako. The draft was given in two stages, where each was further divided into two parts. Trial on master program students provided two advantages, namely: (1) exploring the students' mental model with high academic levels which reinforces the initial allegations relating to the mental model of the hanging object, which also illustrates the lower academic level, and (2) there were some feedbacks related to the structure and content of the test where some of the students are physics teachers at junior/ senior high school. 


\section{Stage 5: Expansion of the Test Concept Coverage}

Based on the conceptions identified from the test trials and input from the participants, further, expansion was carried out by increasing the number of items to determine the test's consistency and coherence aspects. Furthermore, the expansion also led to the development of a framework towards the study aspect, where test items on floating and sinking objects were used to determine the items for hanging objects. In this case, item aspects on floating or sinking objects are used by students when faced with hanging objects. The test expansion involved adapting some items from previous studies, such as Ünal \& Coştu (2005) especially aspects of floating and sinking test, and also summarized by Çepni, Sahin and Ipek (2010) from some studies concerning the alternative conceptions of floating and sinking. The items in the InitialDraft- 1 and InitialDraft- 2 in the form of verbal representations were taken back to enrich the consistency aspect when the representation is changed. From the expansion, it has resulted in the final draft consisting of 30 items with 10 parts.

\section{Stage 6: Expert Validation}

The expert validation carried out focused on the content and construct validity of the test based on Burton \& Mazerolle (2011). This is because the tests prepared are intended to study the coherence and consistency of thinking associated with mental models and patterns of respondent representation. The validation process involved two physics education lecturers. Validated aspects for items in the form of essay include readability, language use, intent/command clarity (conformity of the formulation of the item with indicators), and the appropriateness of the concept. For items that involve image or drawing representation, the validators also validated the additional aspect, such as image clarity. Validation of multiple-choice items includes the stem/ image/options clarity, language use, and homogeneity of the options. Both validators gave ratings on the above aspects for each item with a score of 5 (very good), 4 (good), 3 (moderate), 2 (bad), and 1 (very bad). Data obtained from this rating include content and construct validity. The validation was also carried out to determine the test instructions clarity, integration/coherence to explore the study aspects, test structure (presentation of parts/ questions), and relevance to content such as objects in a liquid fluid. Furthermore, the validators were asked to provide notes or suggestions for each item.

\section{Stage 7: Trial and Proving Validity-Reliability}

After the expert validation, FinalTrial-1 test was carried out by involving respondents. In FinalTrial-1, the test items are presented in 10 parts. Two methods were combined to determine the test reliability, namely the test-retest and interrater agreement. For this purpose, FinalTrial- 2 was carried out involving the same respondents of Final Trial-1.
Table 1: Respondents involved in the trials

\begin{tabular}{ll}
\hline Grade & Number of students \\
\hline Primary school-Grade 5 & 6 \\
Primary school-Grade 6 & 6 \\
Junior Secondary School-Grade 8 & 7 \\
Junior Secondary School-Grade 9 & 6 \\
Senior High School-Grade 11 & 7 \\
Senior High School-Grade 12 & 6 \\
Undergraduate-Year I & 6 \\
Undergraduate-Year II & 6 \\
Undergraduate-Year III & 6 \\
Undergraduate-Year IV & 6 \\
\hline Total & 62 \\
\hline
\end{tabular}

Final Trial-2 was carried out within 14-25 days after FinalTrial-1 based on the time readiness of the respondents. Only 62 respondents involved both FinalTrial-1 and FinalTrial-2 (Table 1). In FinalTrial-2, the test items were presented randomly and not based on parts. Test reliability was determined through an inter-rater agreement by involving two raters to access the consistency of respondents' answers from the two trials. The reliability was determined through Cohen's Kappa coefficient $(\kappa)$ using SPSS V27 (IBM, 2020). The test also covers aspects of the readability or understanding related to the sentence purpose in the test instructions and its items. The respondents provided notes to the instruction, and every item with unclear sentences, assuming there is a bias or word diction that is unsuitable for their education level.

\section{Stage 8: Test Finalization}

The test finalization process is the refinement stage, which includes accommodation and improvement based on notes from expert validation and readability testing, structuring, and presentation stages, as well as layout repair and arrangement.

\section{FINDINGS}

\section{Description of Initial Draft and Trial Results}

The initial draft consists of two parts and five items. The details of the first and second parts are four and one items, respectively. Examples of items in InitialDraft-1 and InitialDraft-2 are shown in Figure 2.

The difference between the two drafts for Part I is that the InitialDraft-1 is an item with a verbal representation, and the InitialDraft-2 is an item with a verbal and picture representation that does not change in question number 4 . In the InitialDraft-2, there is space to answer the test, which is directly presented on the test and do not need a separated sheet. However, this is different from the InitialDraft-1, with Part II for both drafts, shown in Figure 3. 


\section{PART I (a)}

1. Draw floating objects position on water (at 3 points)

2. Draw hanging objects position in water (at 3 points)

3. Draw sinking objects position in water (at 3 points)

4. Why does an abject can float, hang, or sink?

(b) PART I

QUESTION
1. Three objects in the following
are floating on water. Draw the
possibilities of the object's position

2. Three objects in the following are sinking in water. Draw the possibilities of the objects' position
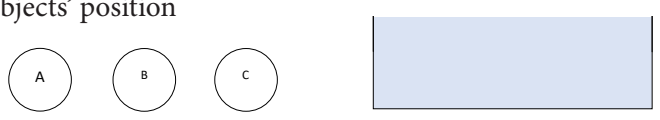

3. Three objects in the following are hanging in the water. Draw the possibilities of the objects' position
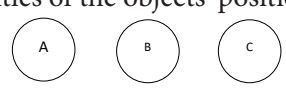

4. Why does an abject float, hang, or sink?

Figure 2: Sample of items (translated) for Part I in (a) Initial Draft-1 and (b) Initial Draft-2

The item in Part-II provides information on the three objects' positions, as shown in Figure 3 (b). This accommodates the possibility of people (respondents) thinking that object $\mathrm{A}$



(a) is floating or 'almost floating', while $\mathrm{C}$ is sinking or 'is almost sinking.' This is consistent with the initial survey, which showed that students generally thought that only object B is hanging. Examples of student responses from trials for the InitialDraft-1 and InitialDraft- 2 are shown in Figure 4.

\section{PART II}

(a) 5. Three objects (A, B, and C) were dropped from different heights into a vessel filled with water. In a stable state, the three of them hold on to a certain position. Object A stays in the almost appearing position on the water surface, Object B is in the middle of the vessel, and Object $\mathrm{C}$ is approaching the bottom of the vessel. How do you think the density of objects $\mathrm{A}, \mathrm{B}$, and $\mathrm{C}$ compares to the density of water? Sort from largest to smallest.

\section{PART II}

\begin{tabular}{|l|l|}
\hline QUESTION & ANSWER \\
\hline Three objects (A, B, and C) are in a vessel \\
filled with water. In a stable state, the \\
three objects are in a position as shown. \\
How do you think the density of objects \\
A, B, and C compares to the density of \\
water?
\end{tabular}

Figure 3: Sample of item Number 5 (translated) for Part II in (a) InitialDraft-1 and (b) Initial Draft-2

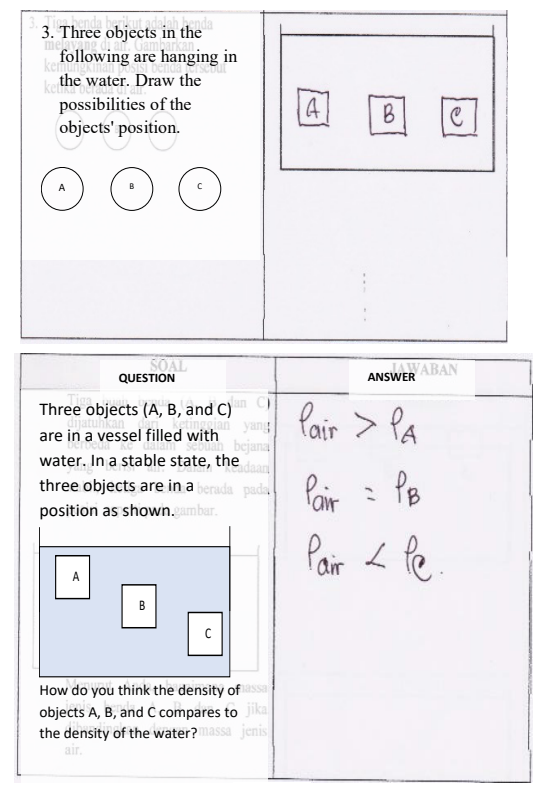

(b)

Figure 4: Samples of student's answer (translated) for (a) InitialDraft-1 and (b) InitialDraft-2 
Although the four items context for Part-I includes floating, hanging, and sinking objects, the focus of the test preparation is to explore mental models and the representation patterns of hanging objects. The context of floating and sinking objects have been previously studied, therefore, the provision of items with these two contexts is intended to determine whether mental models and representation pattern in both contexts affect the context of floating object. In this case, the provision of a floating and sinking context in Part-I is expected to be confirmed in Part II, which specifically explores the hanging object context.

Figure 4 shows that student's answer was following the initial assumption, which stated that people tend to describe hanging objects in a position in the middle of the liquid's depth. There is a unique response from students, especially in item Number 5 from the InitialDraft-1, where the student stated that a stable object near the surface has a smaller density than water. This can be interpreted that objects near the surface are considered as floating objects. Also, the student's answer was confirmed in InitialDraft-2 answer, where the three objects were considered different in terms of density despite being described and drawn as a hanging object. The answer $\rho_{\text {water }}$ $>\rho_{A}, \rho_{\text {water }}=\rho_{B}$, and $\rho_{\text {water }}<\rho_{C}$ means that the respondent considered all three objects to have different properties in terms of density. The sample answers above show that the draft test can accommodate the initial assumption and confirm the initial survey on the tendency of hanging objects to be drawn in the middle of the depth of liquid.

\section{The Results of Rational and Empirical Validity of the Final Draft}

Qualitative descriptions of the aspects of test validity from the two validators are shown in Table 2. Table 3 shows the summary and average scores from the validation of the four multiple-choice items.

Based on Table 2 and Table 3, it can be stated that the expert validation results generally show both individual and combined items with the validated aspect in the very good category. The tables also showed several items that need improvement relating to the aspect of intent/command clarity. Some validators' suggestions were accommodated in the final test.

After the validation by the experts, the developed model was tested to determine the functioning and readability. Functioning is related to the ability of the test to be used to explore mental models and external representation patterns. The test reliability is based on qualitative data by examining the consistency of the respondents' answers for twice trials with two arrangement formats. In FinalTrial-1, the test items were arranged in parts, while in FinalTrial-2 were randomly

Table 2: The results of validation (content and face validity) by two experts

\begin{tabular}{|c|c|c|c|c|}
\hline \multirow[b]{2}{*}{ Validated aspects } & \multicolumn{3}{|c|}{ Average Score } & \multirow[b]{2}{*}{ Comments/suggestions from the validators } \\
\hline & Expert-1 & Expert -2 & Average & \\
\hline Clarity of instructions & 4,0 & 4,0 & 4,0 & \multirow{9}{*}{$\begin{array}{l}\text { It needs to be clarified the types of floating, sinking, and hanging } \\
\text { objects. It should only mention the item name (Number } 1,2 \text {, } \\
\text { and } 3 \text { ) } \\
\text { It needs to be clarified types of floating, sinking, or hanging } \\
\text { objects. Or at least it is mentioned from the same material } \\
\text { (Number } 6,7 \text {, and } 8 \text { ) } \\
\text { It needs to be clarified whether the properties of floating, sinking, } \\
\text { or hanging objects filled with air or objects that temporary } \\
\text { floating, sinking, or hanging then filled with air? (Number } 28 \text {, } \\
29 \text {, and } 30 \text { ) } \\
\text { Test items should be arranged randomly to reduce the bias where } \\
\text { one item being used to answer other items }\end{array}$} \\
\hline Readability* & 5,0 & 4,0 & 4,5 & \\
\hline Language Use * & 5,0 & 4,0 & 4,5 & \\
\hline Image clarity * & 5,0 & 4,5 & 4,8 & \\
\hline Test presentation structure & 5,0 & 4,0 & 4,5 & \\
\hline Truth of concept * & 4,9 & 5,0 & 4,9 & \\
\hline Clarity of intent/ instructions * & 4,5 & 3,9 & 4,2 & \\
\hline Cohesion/coherence of items & 5,0 & 4,0 & 4,5 & \\
\hline Relevance with content & 5,0 & 5,0 & 5,0 & \\
\hline
\end{tabular}

${ }^{\star}$ Calculated from a combined score of 26 items

Table 3: The validation (content and face validity) by two experts for multiple-choice test items

\begin{tabular}{llll}
\hline & \multicolumn{2}{c}{ Average Score } \\
\cline { 2 - 4 } Validated aspects & Expert -1 & Expert -2 & Average (combination) \\
\hline Stem Clarity & 5,0 & 4,0 & 4,5 \\
Stem images Clarity ${ }^{*}$ & 5,0 & 5,0 & 5,0 \\
Image Option Clarity & 5,0 & 5,0 & 5,0 \\
Homogeneity of options & 5,0 & 5,0 & 5,0 \\
The writing of options order & 5,0 & 5,0 & 5,0 \\
The functioning of option & 5,0 & 5,0 & 5,0 \\
\hline
\end{tabular}

*Only on 1 of 4 items 
arranged. FinalTrial-2 was carried out for 14-25 days after FinalTrial-1 to reduce the bias on testing repetition in the form of carry-over (Putt, 2005) or testing effect. This was not based on the memory of previous answers, and there was no additional knowledge due to the learning experience.

Based on the FinalTrial-1 and FinalTrial-2 data, a rating was performed to determine the agreement between the two testing results by involving two raters. Reliability is also seen from the degree of agreement between the two raters in determining the respondents' consistent answers in categories 4 (very consistent), 3 (quite consistent), 2 (less consistent), and 1 (inconsistent). Furthermore, the first category of very consistent (score 4) and quite consistent (score 3) was re-categorized into the strong consistency category and the second category of less consistent (score 2) and inconsistent (score 1) was re-categorized as a new category of weak consistency. Based on the rating and contingency table of the re-category results, a Cohen's Kappa (к) score of 0.715 ( $p=$ $0.000)$ is obtained and in the high category. This means that the test is reliable in exploring the study aspects.

In the trials, respondents were also asked to provide notes or suggestions on items with meanings that are difficult to understand both in terms of content and instruction. Samples of Edy's (pseudonym) answers for one of the items in the two trials are shown in Figure 5.

Figure 5 shows consistency in the Edy's answers on trial for a span of 14 days. Similar answers also occur in other items, which illustrate that the test items are carried out based on their knowledge and mental models. A similar representation pattern for two tests (test-retest) shows that the respondent working on the test used the knowledge and mental model. Therefore, the test is reliable to use on a broader scale to assess aspects of the study.

\section{General Descriptions of Finalization Result}

Several items were revised based on the trial results and the respondents' notes or suggestions. For example, items Number 1-3 (from FinalTrial-1) are revised in the aspect of the introductory sentence. Besides refinement of the sentence editorial on several items, a revision on the statement of questions and image for item Number 27 (FinalTrial-1) was also made with improvements on the layout.

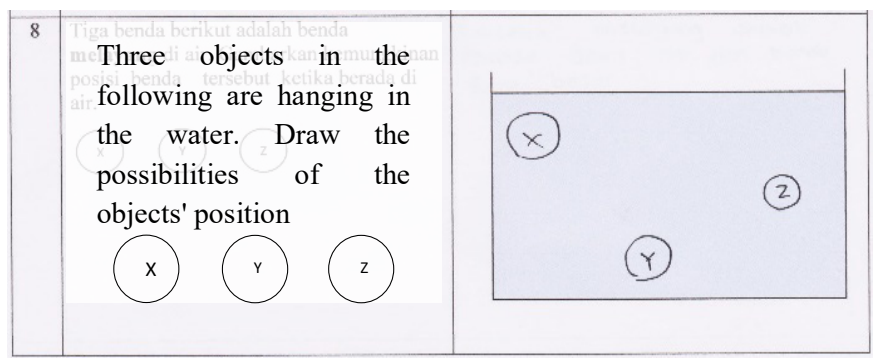

Data on FinalTrial-1 and FinalTrial-2 show that respondents' answers tend not to be influenced by the test arrangement format between the item grouping and the random format. However, based on the validator's suggestion that is to reduce the bias possibility, and facilitate the presentation and fulfilment of good test rules, a random format is chosen. This ensures that the test items are not presented based on the concept or drawing groups and the order of floating-hangingsinking concepts, as commonly discussed in the textbooks. Compilation in a random format for respondents does not eliminate the distribution of test items based on the group in the data analysis process. Therefore, the division of groups is needed for ease of analysis towards the data of these test results as shown in Table 4.

Table 4 also shows a re-grouping of test items from 10 to 4 parts based on its function in building coherence to explore the study aspects. The grouping is to simplify and facilitate the data analysis process when the test is applied, which describes the position and support towards the aspects to be explored, as shown in Table 4 and Figure 6.

\section{Layout Arrangement}

The layout or display arrangement of test performed includes the identity's structure, instructions, and the test items presentation order. Based on the grouping in Table 4 and the coherence structure in Figure 6, the objects' codes in the form of one letter in the items are rearranged to form sequential single letters. For example, Object B in item Number 6 is changed to Object A, Object F in Number 7 becomes Object B, etc. The arrangement is also carried out in the answer column by providing more space for respondents to write their answers, especially for items that ask for a brief explanation. This is because the test answer sheets and questions are presented in parallel on a column format of No. Item-Question-Answer. The result of the test development process is presented in the Appendix A.

\section{Discussion and Conclusion}

An example of the items' role in building coherence and in exploring aspects of the study was shown in Figure 6. Items Number 4 and 11 play a role in exploring how respondents



Figure 5. Comparison of samples from (a) FinalTrial-1 and (b) FinalTrial-2 results by Edy 
Table 4: The grouping of test items is based on the mental model and the targets representation pattern identified in the test, changes in item numbers and the explored aspects

\begin{tabular}{|c|c|c|c|c|}
\hline \multirow[b]{2}{*}{ Item Group } & \multirow[b]{2}{*}{ Description } & \multicolumn{2}{|c|}{ No. Item } & \multirow[b]{2}{*}{ New Group } \\
\hline & & Old & New & \\
\hline Part I & $\begin{array}{l}\text { Drawing } 3 \text { points for the floating, sinking, and hanging positions, as well } \\
\text { as the causes of objects in that position. }\end{array}$ & $1,2,3,4$ & $4,11,21,23$ & A \\
\hline Part II & $\begin{array}{l}\text { Comparing the density of } 3 \text { hanging objects for } 3 \text { positions towards the } \\
\text { water density based on the description of objects position. }\end{array}$ & 5 & 29 & B \\
\hline Part III & $\begin{array}{l}\text { Drawing the possible positions of } 3 \text { floating, sinking, and hanging objects } \\
\text { each. }\end{array}$ & $6,7,8$ & $1,5,14$ & A \\
\hline Part IV & $\begin{array}{l}\text { Comparing the density of } 3 \text { hanging objects towards the water density based } \\
\text { on the objects' positions. }\end{array}$ & 9 & 12 & B \\
\hline Part V & $\begin{array}{l}\text { Choosing the piece position assuming a floating object is divided into } 2 \\
\text { parts with different sizes. }\end{array}$ & 10 & 10 & $\mathrm{C}$ \\
\hline Part VI & $\begin{array}{l}\text { Determine and explain the position of the object drawn close to the liquid's } \\
\text { surface or near the bottom of the vessel. }\end{array}$ & 11,12 & 17,22 & $\mathrm{C}$ \\
\hline Part VII & $\begin{array}{l}\text { Choosing the factors that determine the floating/sinking objects and the } \\
\text { possible position of } 2 \text { objects from the same material in different shapes }\end{array}$ & $13,14,15$ & $24,28,2$ & A \\
\hline Part VIII & $\begin{array}{l}\text { Predicting the effect of making holes or cavities on floating, sinking or } \\
\text { hanging objects }\end{array}$ & $\begin{array}{l}16,17,18,19 \\
20,21\end{array}$ & $\begin{array}{l}9,6,13,18 \\
15,7\end{array}$ & $\mathrm{D}$ \\
\hline Part IX & $\begin{array}{l}\text { Describing each piece's position assuming a floating or sinking object is } \\
\text { divided into two or three pieces and determining the effect of adding water } \\
\text { to the hanging object position. }\end{array}$ & $\begin{array}{l}22,23,24,25 \\
26,27\end{array}$ & $\begin{array}{l}20,25,30,8 \\
26,16\end{array}$ & $\mathrm{C}$ \\
\hline Part X & $\begin{array}{l}\text { Predicting the event assuming a hollow is filled with air on a floating, sinking } \\
\text { or hanging object }\end{array}$ & $28,29,30$ & $3,19,27$ & $\mathrm{D}$ \\
\hline
\end{tabular}

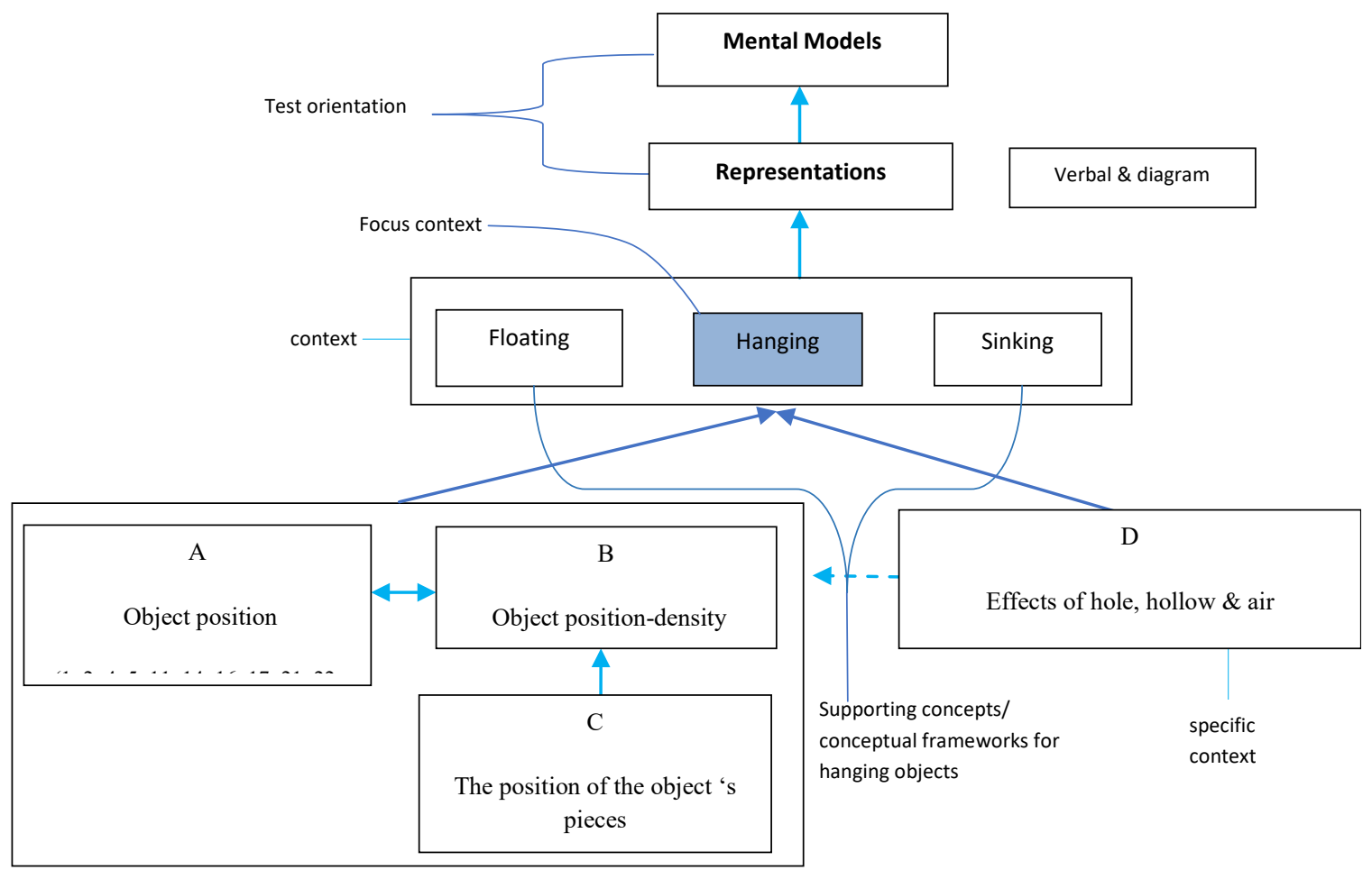

Figure 6: Schematic of position and item support/group of test items in building coherence to explore the study aspects 
draw objects positions in a floating and sinking state, which are similar to Numbers 1 and 5. From the classical test theory, these items do not fulfil the requirements in terms of the difficulty and differentiation level. Furthermore, in developing this test, the items were retained to uncover the initial suspicion that the mental model and the respondents' external representations pattern from the context of the floating or sinking object affected the hanging objects' context (Numbers 21 and 14).

Based on Figure 6, another form of test item coherence is shown in item Number 12 (Group B) with respondents' answers confirmed in Numbers 14, 17, 21, 22, and 29 of Group C. The respondents' answers are further confirmed through Numbers $3,6,7,9,13,15,18,19$, and 27 of Group D for the specific context of hollow, hollow objects, and the influence of air in the hollow. Another example is items Number 24 and 28 in Group A, which explore the variables that determine the floating or sinking of objects. In both items, respondents can choose one or more of the seven variables provided, which were confirmed in items Number 12 and 29 of Group B regarding density. This was further confirmed in Group D, which explores mental models and representation patterns concerned with the existence of hole, hollow, and air on the objects' properties and positions implicitly related to density. Based on a review on the examples of test results above, it is stated that individual or group test items play a role in building coherence to achieve the test objectives. This confirms the ability to use the feasibility test to explore the study aspects on a broader scale.

Furthermore, it is used to determine the ability of the item to play a role in exploring mental models and representation patterns by examining respondents' answers in the trial. In the case of a hanging object in the water, one of the respondents named Ainun (pseudonym) stated that the object tends to stay hanging if on the object is made a hollow. If the hollow is filled with air, which also makes it floats. Similarly, assuming the hollow is filled with air, the hollow makes the object condition from hanging or sinking to floating. The mental model adopted by Ainun is similar to finding of (Smith et al., 1997) for Class 8 students, where the air is seen as an active force that pulls things up. Ainun did not consider the change of the object's density if on the object is made a hollow. This is different from Rudy (pseudonym) which stated that if on the hanging object is made a hollow, then object will float. If the hollow is filled with air, then the object will sink. According to Rudy, the properties of floating, hanging, and sinking of objects are dependent on their density.

The mental models that are successfully explored through this test are then named based on their characteristics The identified mental models are named using methods proposed by Vosniadou (2002), Harrison and Treagust (2000), Shen et al. (2017), and Nongkhunsarn et al. (2019)Roi-et, Thailand. The teaching and learning about fluid through science technology and society (STS. For example, model adopted by Ainun above can be named "Air as Floater", and Rudy's model can be named "Density-Based Model". If a hole is made in the floating, hanging, or sinking objects, then the students' mental model is named, such as the density-based model, mass-based model, etc. If a respondent relates the effect of hole to density, the answer will be termed "density-based model" abbreviated as DbM. If the respondent refers to the object's mass, the mental model is named "mass-based model" MbM). urthermore, the mental models were categorized into a hierarchy according to Vosniadou and Ioannides (1998) and Kurnaz and Eksi (2015), i.e. initial model (IM), synthetic model (SyM), and scientific model (ScM).

The examples of the models above show that the test can accommodate and explore the models' diversity adopted by each respondent. Another finding of the trial shows that primary school students predominantly describe the position of the pieces of floating, sinking, or hanging objects based on its size. Smaller pieces are consistently depicted in a higher position than larger pieces, which shows that the test has good predictive validity due to its ability to make predictions. These characteristics reinforce the test feasibility to be used on a broader scale in exploring mental models and the representation patterns.

The results showed that the developed test fulfilled the validity and reliability requirements used in the exploration of mental models and representation patterns. The test also has predictive validity where were previously thought mental models and representation patterns are explored. Furthermore, the test items also have coherent and integrated characteristics to build a good test construct to accommodate the diversity of thinking of students as the effect of curriculum and environment for elementary school (grade 5, grade 6), junior/ senior high school, and undergraduate.

\section{Limitation}

This test is only appropriate for exploring mental models and external representation patterns towards hanging objects in a fluid. The results provided through the using of this test are qualitative data, which are related to the test description. The test output does not take the form of a respondent's score on the item because there is no judgment for correct or incorrect answers. In this test, there are multiple-choice items provide more than one correct answer.

\section{References}

Adbo, K., \& Taber, K. S. (2009). Learners' mental models of the particle nature of matter: A study of 16-year-old Swedish science students. International Journal of Science Education, 31(6), 757-786. https://doi.org/10.1080/09500690701799383

Buckley, B. C., \& Boulter, C. J. (2000). Investigating the role of representations and expressed models in building mental 
models. In Developing Models in Science Education. https:// doi.org/10.1007/978-94-010-0876-1_6

Burton, L. J., \& Mazerolle, S. M. (2011). Survey instrument validity part i: Principles of survey instrument development and validation in athletic training education research. In Athletic Training Education Journal,6 (1), 27-35). https://doi. org/10.4085/1947-380x-6.1.27

Castillo, R. D., Waltzer, T., \& Kloos, H. (2017). Hands-on experience can lead to systematic mistakes: A study on adults' understanding of sinking objects. Cognitive Research: Principles and Implications, 2(1). https://doi.org/10.1186/s41235-0170061-8

Çepni, S., Şahin, Ç., \& Ipek, H. (2010). Teaching floating and sinking concepts with different methods and techniques based on the 5E instructional model. Asia-Pacific Forum on Science Learning and Teaching, 11(2), 1-16.

Chien, S., Hsiung, C., \& Chen, S. (2009). The development of young children's science-related concept regarding "floating and sinking." Asia-Pacific Journal of Research in Early Childhood Education, 3(2), 73-88.

Cotton, W., Lockyer, L., Brickell, G. J., \& Brickell, G. (2009). A journey through a design-based research project a journey through a design-based research project. Proceedings of World Conference on Educational Multimedia, Hypermedia and Telecommunications 2009, 2009, 1364-1371.

Duit, R. (2007). Science education research internationally: Conceptions, research methods, domains of research. Eurasia Journal of Mathematics, Science and Technology Education, 3(1), 3-15. https://doi.org/10.12973/ejmste/75369

Gette, C. R., Kryjevskaia, M., Stetzer, M. R., \& Heron, P. R. L. (2018). Probing student reasoning approaches through the lens of dualprocess theories: A case study in buoyancy. Physical Review Physics Education Research, 14, 010113. https://doi.org/10.1103/ PhysRevPhysEducRes.14.010113

Greca, I. M., \& Moreira, M. A. (2000). Mental models, conceptual models, and modelling. International Journal of Science Education, 22(1), 11. https://doi.org/10.1080/095006900289976

Harrison, A. G. (2001). How do teachers and textbook writers model scientific ideas for students? Research in Science Education, 31(3), 401-435. https://doi.org/10.1023/A:1013120312331

Harrison, A. G., \& Treagust, D. F. (2000). A typology of school science models. International Journal of Science Education, 22(9), 1011-1026. https://doi.org/10.1080/09500690041 6884

Havu-Nuutinen, S. (2005). Examining young children's conceptual change processin floating and sinking from a social constructivist perspective. International Journal of Science Education, 27(3), 259-279. https://doi.org/10.1080/09500690420002 43736

Hegarty, M., Stieff, M., \& Dixon, B. L. (2013). Cognitive change in mental models with experience in the domain of organic chemistry. Journal of Cognitive Psychology, 25(2), 220-228. https://doi.org/10.1080/20445911.2012.725044

Heron, P. R. L., Loverude, M. E., Shaffer, P. S., \& McDermott, L. C. (2003). Helping students develop an understanding of Archimedes' principle. II. Development of research-based instructional materials. American Journal of Physics, 71(11), 1188-1195. https://doi.org/10.1119/1.1607337
IBM. (2020). SPSS V27.

Johnson-Laird, P. N. (2001). Mental models and deduction. Trends in Cognitive Sciences, 5(10), 434-442. https://doi.org/10.1016/ S1364-6613(00)01751-4

Kafiyani, F., Samsudin, A., \& Saepuzaman, D. (2019). Development of four-tier diagnostic test (FTDT) to identify student's mental models on static fluid. Journal of Physics: Conference Series, 1280(5). https://doi.org/10.1088/1742-6596/1280/5/052030

Kohn, A. S. (1993). Preschoolers' reasoning about density: Will it float? Child Development, 64(6), 1637-1650. https://doi. org/10.1111/j.1467-8624.1993.tb04204.x

Kurnaz, M.A. and Eksi, C. 2015. An Analysis of High School Students' Mental Models of Solid Friction in Physics. Educational Sciences: Theory \& Practice 15(3): 787-95.

Larsson, J. (2016). Emergent science in preschool: the case of floating and sinking. International Research in Early Childhood Education.

Minogue, J., \& Borland, D. (2016). Investigating students' ideas about buoyancy and the influence of haptic feedback. Journal of Science Education and Technology. https://doi.org/10.1007/ s10956-015-9585-1

Nongkhunsarn, A., Yuenyong, C., Tupsai, J., \& Sranamkam, T. (2019). Grade 11 student's mental model of fluid and analytical thinking in science teaching through science technology and society (STS) approach. Journal of Physics: Conference Series, 1340(1). https://doi.org/10.1088/1742-6596/1340/1/012043

Putt, M. E. (2005). Carryover and sequence effects. Encyclopedia of Statistics in Behavioral Science, 1, 197-201. https://doi. org/10.1002/0470013192.bsa070

Qonita, Q., Syaodih, E., Suhandi, A., Maftuh, B., Hermita, N., Samsudin, A., \& Handayani, H. (2019). How do kindergarten teachers grow children science process skill to construct float and sink concept? Journal of Physics: Conference Series, 1157(2). https://doi.org/10.1088/1742-6596/1157/2/022017

Reeves, T. C. (2000). Enhancing the worth of instructional technology research through "design experiments" and other development research strategies. Educational Technology, April, 1-15. http:// it.coe.uga.edu/ treeves/AERA2000Reeves.pdf

Scott, R. J., Cavana, R. Y., \& Cameron, D. (2016). Mechanisms for understanding mental model change in group model building. Systems Research and Behavioral Science, 33(1), 100-118. https:// doi.org/10.1002/sres.2303

Shen, J., Liu, O. L., \& Chang, H. Y. (2017). Assessing students' deep conceptual understanding in physical sciences: an example on sinking and floating. International Journal of Science and Mathematics Education, 15(1), 57-70. https://doi.org/10.1007/ s10763-015-9680-z

Shivakumar, M. (2016). The law of buoyancy force. International Journal of Engineering Research \& Technology, 5(02), 183-185. https://doi.org/10.17577/ijertv5is020264

Smith, C., Maclin, D., Grosslight, L., \& Davis, H. (1997). Teaching for understanding: A study of students' preinstruction theories of matter and a comparison of the effectiveness of two approaches to teaching about matter and density. In Cognition and Instruction,15 (3), 317-393. https://doi.org/10.1207/ s1532690xci1503_2

Teo, T. W., Yan, Y. K., \& Ong, W. L. M. (2017). An investigation of Singapore preschool children's emerging concepts of floating 
and sinking. Pedagogies: An International Journal, 12(4), 325339.. https://doi.org/10.1080/1554480X.2017.1374186

Ünal, S., \& Coştu, B. (2005). Problematic issue for students: Does it sink or float? Asia-Pacific Forum on Science Learning and Teaching, 6(1), 1-16.

van Schijndel, T. J. P., van Es, S. E., Franse, R. K., van Bers, B. M. C. W., \& Raijmakers, M. E. J. (2018). Children's mental models of prenatal development. Frontiers in Psychology, 9, 1835. 1-13. https://doi.org/10.3389/fpsyg.2018.01835

Viyanti, Cari, Sunarno, W., \& Prasetyo, Z. K. (2017). The development rubrics skill argued as alternative assessment floating and sinking materials. Journal of Physics: Conference Series, 909(1). https://doi.org/10.1088/1742-6596/909/1 /012057

Vosniadou, S. (2002). Mental models in conceptual development. In: Magnani L., ., Nersessian N.J. (eds) Model-based reasoning. Springer, Boston, MA. https://doi.org/10.1007/978-1-46150605-8_20.

Vosniadou, S. and Ioannides, C. (1998) 'From conceptual development to science education: A psychological point of view', International Journal of Science Education, 20(10), pp. 1213-1230. doi: 10.1080/0950069980201004. 


\section{Appendix A \\ TEST OF OBJECTS IN LIQUID}

School/University:

Class
Name

Mobile phone/WA :

\section{INSTRUCTION}

a. Read the problems in the following, detailly.

b. Solve the all problems, sequentially. Avoid returning to previous problem (s) to make correction(s) after you solve a problem.

c. Duration: 45 minutes

d. For several problems, use remarks below:

- Assume the water density is not change because of a pressure (incompressible)

- An object that is cut or divided into several parts is a homogeneous object.

- Hole: empty space through two (or more) surfaces of an object, not closed. Example: a pipe without caps at both ends.

- Hollow: closed and empty space (vacuum/no air). Example: a pipe is closed at both ends (and the space does not contain air)

\section{PROBLEM AND ANSWER SHEET}

\begin{tabular}{l} 
No. Problem \\
\hline 1 \\
position in the water
\end{tabular}
happen?

4 Draw the position of floating objects on the water (at 3 points).

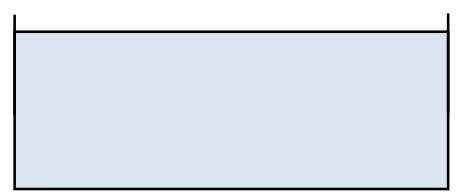

5 The following three objects are sinking in water. Draw the objects' possible position in the water.
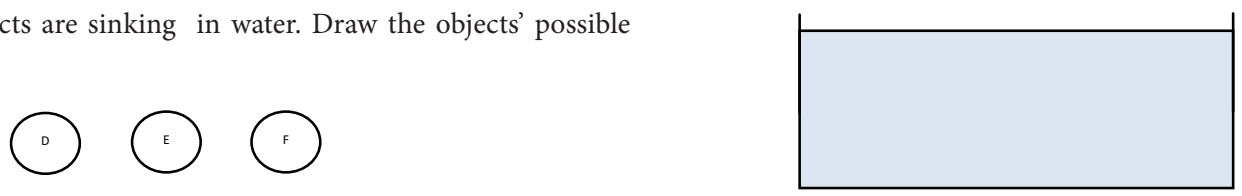


\begin{tabular}{lll}
\hline No. & Problem & Answer \\
\hline 6 & Object A is an object sinking in water. If a hole is made in the object, what would &
\end{tabular}
happen?

$7 \quad$ Object $\mathrm{B}$ is an object hanging in water. If a hollow is made in the object, what would happen?

8 In a stable state in water, the position of Object $\mathrm{C}$ is depicted as in the image below. If Object $\mathrm{C}$ is cutted into 2 pieces. The first part is $1 / 4$ (one-fourth) part and the second $3 / 4$ (three-fourth) part. Draw the best positions for the two pieces.
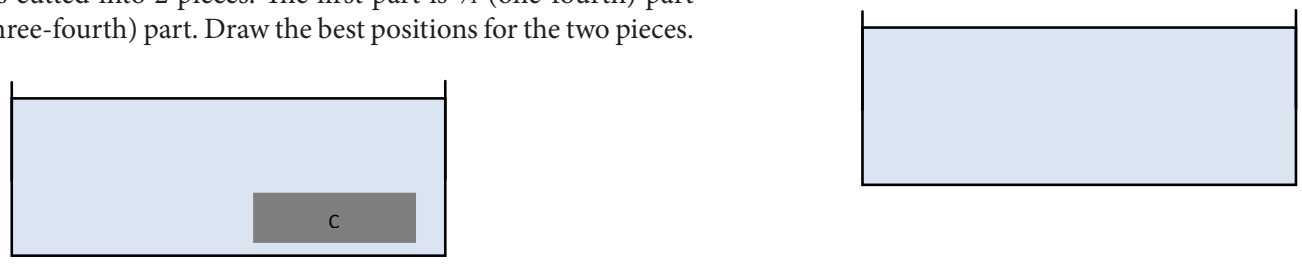

9 Object $\mathrm{D}$ is an object floating on water. If a hole is made in the object, what would happen?

10 Object $\mathrm{K}$ floats on a liquid with the position as shown below. If Object $\mathrm{K}$ is divided into two parts ( $\mathrm{M}$ and $\mathrm{L}$ ) of different sizes. Then both of them are put into the same liquid one by one. Which image shows the correct position of the two objects?

K
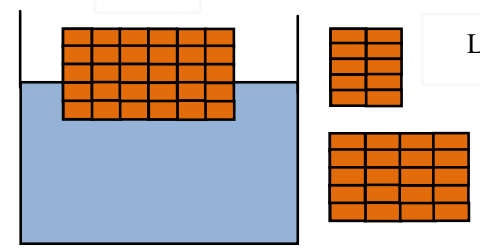

L

L

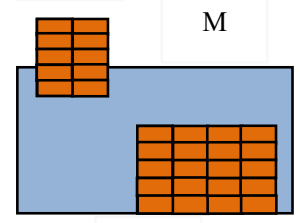

a
L M

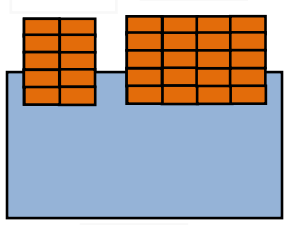

b

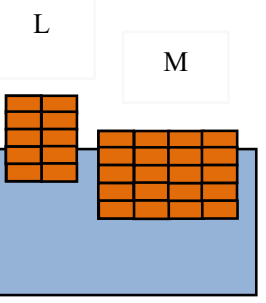

c
L M

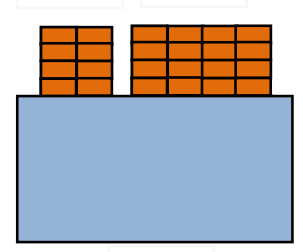

d

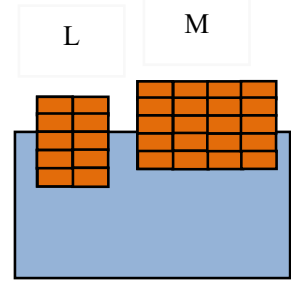

11 Draw the position of the sinking object in the water (at 3 points). 




13 Object $\mathrm{E}$ is a hanging object in water. If a hole is made in the object, what would happen?

14 The following three objects are objects hanging in water. Draw the possibilities of the objects' position.
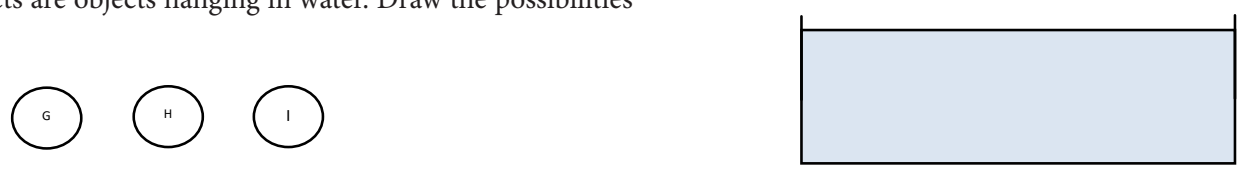

15 Object $\mathrm{F}$ is an object sinking in water. If a hollow is made in the object, what would happen?

16 Object $\mathrm{G}$ is in the water in the position as shown. If the water in the vessel is added so that the vessel is almost full, what would happen? Draw the position of the object!
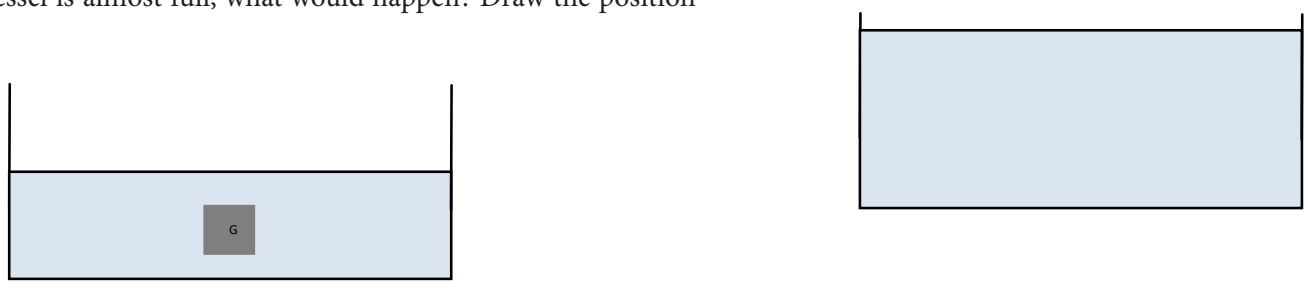

17 The object in the vessel filled with water is in the position as shown. How do you think the object is? Give explanations!

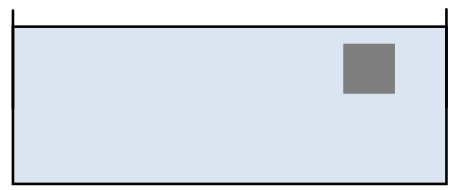

18 Object $\mathrm{H}$ is an object floating on water. If a hollow is made in the object, what would happen?

19 A hollow object is sinking in water. If the hollow is filled with air, what would happen? 


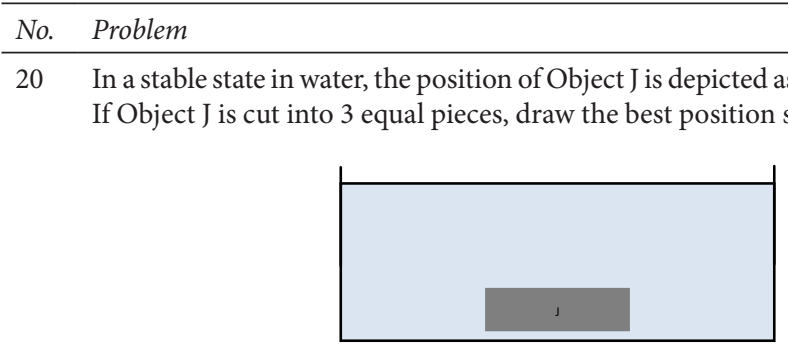

\section{Answer}

In a stable state in water, the position of Object $\mathrm{J}$ is depicted as in the image below.

Object $\mathrm{J}$ is cut into 3 equal pieces, draw the best position sfor the three pieces.

21 Draw the position of the hanging objects in the water (at 3 points).



22 The object in the vessel filled with water is in the position as shown. How do you think the object is? Give explanations



23 Why do objects float, hang or sink in water? Give a brief explanation!

24 Based on your opinion, what do determine the state of a floating object? You may choose more than one if needed. Give an example of each of your choices!
a. Weight of the object
b. Gravity
c. The mass of the object
d. The density of the object
e. Density of the liquid
f. The volume of the object g. Volume of liquid

Give a reason to each of your choices!

25 In a stable state in water, the position of Object $\mathrm{N}$ is depicted as in the image below. If $\mathrm{N}$ is cutted into 3 pieces, draw the best positions for the three pieces.

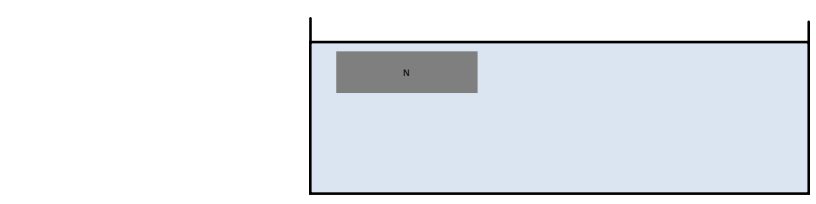

\begin{tabular}{|llllll|}
\hline $\mathrm{a}$ & $\mathrm{b}$ & $\mathrm{c}$ & $\mathrm{d}$ & $\mathrm{e}$ & $\mathrm{f}$ \\
\hline
\end{tabular}

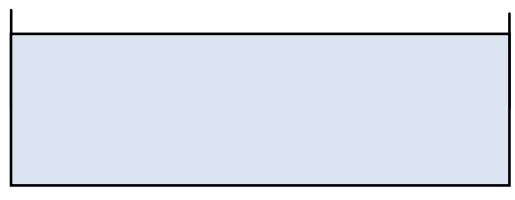

26 In a stable state in water, the position of Object $\mathrm{O}$ is depicted as in the image below. If $\mathrm{O}$ is cutted into 2 parts. The first part is $1 / 4$ (one-fourth) and the second $3 / 4$ (three-fourth). Draw the best positions for the two pieces.


27 An object has a hollow is hanging in water. If the hollow is filled with air, what would happen? 


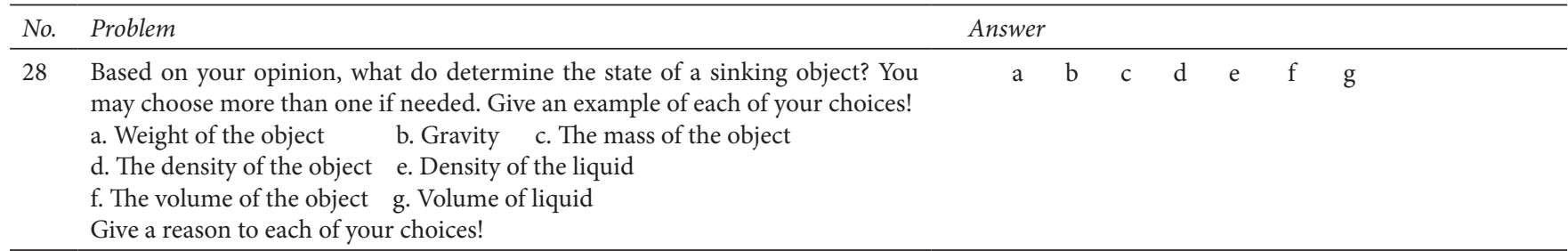

29 Three objects (D, E and F) were dropped from different heights into a vessel filled with water. In a stable state, the objects hold in to certain positions. Object $\mathrm{D}$ stays in the almost appearing in the water surface, Object $\mathrm{E}$ is in the middle of the vessel and Object $\mathrm{F}$ is approaching the bottom of the vessel. How do you think the density of $\mathrm{D}, \mathrm{E}$ and $\mathrm{F}$ compared to the density of water?

30 In a stable state in water, the position of Object $\mathrm{P}$ is depicted as in the image below. If Object $\mathrm{P}$ is cutted into 3 equal pieces, draw the most appropriate positions for the three pieces.
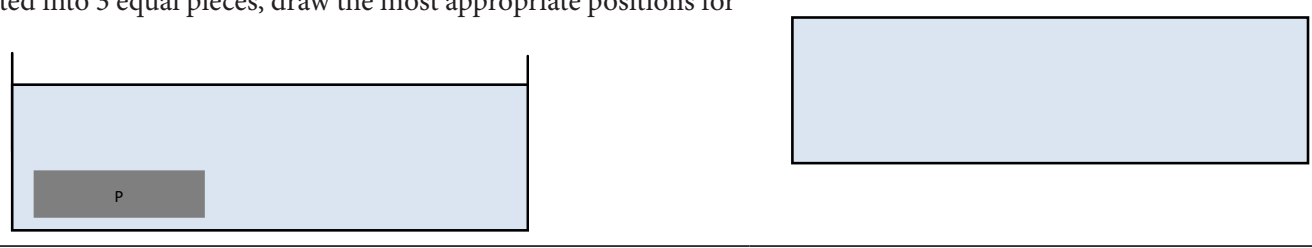